\title{
Thermoelectric Modelling and Optimization of Offshore Windfarm Export Systems -
} State of the Art

\author{
Kazmi, Syed Hamza Hasan; Holbøll, Joachim; Olesen, Thomas Herskind ; Sørensen, Troels Stybe
}

Published in:

Proceedings of 2019 Global Power, Energy and Communication Conference

Link to article, DOI:

10.1109/GPECOM.2019.8778513

Publication date:

2019

Document Version

Peer reviewed version

Link back to DTU Orbit

Citation (APA):

Kazmi, S. H. H., Holbøll, J., Olesen, T. H., \& Sørensen, T. S. (2019). Thermoelectric Modelling and Optimization of Offshore Windfarm Export Systems - State of the Art. In Proceedings of 2019 Global Power, Energy and Communication Conference (pp. 331-6). IEEE. https://doi.org/10.1109/GPECOM.2019.8778513

\section{General rights}

Copyright and moral rights for the publications made accessible in the public portal are retained by the authors and/or other copyright owners and it is a condition of accessing publications that users recognise and abide by the legal requirements associated with these rights.

- Users may download and print one copy of any publication from the public portal for the purpose of private study or research.

- You may not further distribute the material or use it for any profit-making activity or commercial gain

- You may freely distribute the URL identifying the publication in the public portal 


\section{Thermoelectric Modelling and Optimization of Offshore Windfarm Export Systems - State of the Art}

\author{
Syed Hamza Hasan Kazmi \\ Electrical Systems \\ Ørsted Offshore \\ Gentofte, Denmark \\ syeka@orsted.dk
}

\author{
Joachim Holbøll \\ Dept. of Electrical Engg. \\ Tech. University Denmark \\ Lyngby, Denmark \\ jh@elektro.dtu.dk
}

\author{
Thomas Herskind Olesen \\ Electrical Systems \\ Ørsted Offshore \\ Fredericia, Denmark \\ thole@orsted.dk
}

\author{
Troels Stybe Sørensen \\ Electrical Systems \\ Ørsted Offshore \\ Gentofte, Denmark \\ troso@orsted.dk
}

\begin{abstract}
With recent developments and cost reduction, offshore windfarms are set to lead the energy markets of the west by 2030. This development can further be accelerated if the wind intensive periods can be utilized efficiently by optimizing the limited network capacity and if the energy output is increased during contingency outages. Therefore, dynamic rating operation of components that are primary system bottlenecks becomes crucial. This paper identifies potential bottlenecks in offshore windfarm export systems and provides an extensive state-of-the-art review of dynamic thermoelectric models which are applicable for real-time loadability assessment of the identified components. The loadability of these components is directly dependent on their thermal state, which is evaluated based on analytical solutions of the dynamic thermoelectric model, including the complicated heat transfer and temperature development phenomena in the identified components. Moreover, potential risks of using these models for offshore windfarm applications are also identified.
\end{abstract}

Keywords - Dynamic thermal rating, cable, thermoelectric modelling, offshore windfarm, renewable integration, transformer

\section{INTRODUCTION}

Wind energy is a major contributor to the annual electricity generation in Denmark [1] and it is projected to increase even further by 2030 [2] in order to keep up with the targets defined by the Danish Government's 'Energy Agreement' of 2018 [3]. A sizable portion of this increment is bound to be delivered by Offshore Wind Power Plants (OWPPs). But bottlenecks in OWPPs export systems and the system improvement costs related to resolving these bottlenecks are major barriers to this prognosis [4], [5].

Some bottlenecks can be removed and the unused potential of some of the major components of OWPP export systems can be exploited by switching to Dynamic Thermal Rating (DTR) instead of using static rating based on conservative assumptions including continuous full load, high solar radiation, and fixed ambient temperatures [6]. The majority of publications on DTR so far have focused on overhead lines (OHLs), including extensive thermal modeling, inclusion of weather forecasts [7], [8] and innovative real-time sag measurement [9] to effectively increase the dynamic rating based operation. However, OHLs do not play such an influential role in the debottlenecking of offshore windfarms.

Therefore, the attention must shift to all the remaining components which include transformers, subsea and underground cables, shunt reactors, HV filters, compensators, MV/HV switchgears, CTs, VTs, Circuit Breakers etc. These components can be prioritized based on their impacts on system's loadability and bottlenecks. Utilization of real-time monitoring techniques can contribute to raise the possible loading of some of these components above the static limit $99 \%$ of the time. Similarly, a handful of publications claim that the conservative static limits can be exceeded by $30 \%$ of the limit about $90 \%$ of the time using the DTR principle [10].
The characteristic loadability of underground cables is typically based on the international standard IEC 60287 [11] and the cyclic ampacity is based on IEC 60853 [12] along with certain recent CIGRE publications discussing the optimization of these standard models using Distributed Temperature Sensing (DTS) and Real Time Thermal Rating [10], [13]. This provides sufficient information for $\mathrm{HV}$ cables, but little to no work has been done for rest of the identified components.

The dynamic loading guides for power transformers disseminated by IEEE [14] and IEC [15] have evolved since the early 1990's and these guides are still subjects of development, whereas the CIGRE Brochure 659 [16] provides an extensive overview on the topic. The integration of distributed generation in existing electrical infrastructure has shifted the focus towards short term dynamic rating of transformers as well, which can be used for OWPP export system optimization and debottlenecking [17], [18].

The measurement of critical temperatures variation with load in HV/MV cables and oil-filled transformers using fibreoptic sensors like DTS is often costly and even unavailable. Moreover, these solutions are not perfect for real-world applications because the sensors may not be able to locate hotspots or may not determine the exact conductor or winding temperature. Therefore, dynamic thermal estimation of these components is performed using thermal modeling techniques, predominantly based either on the Finite Element Method (FEM) and Computational Fluid Dynamic (CFD) [16], [19] or on Thermoelectric Equivalent (TEE) circuits representing the heat flow equations using the thermoelectric analogy [20]. The accuracy of CFD and FEE modelling is higher than the latter approach and these can also allow determination of complete temperature distribution under the assumption that all thermal parameters are known. But the advantages offered by TEE models like the simplicity of design, easy availability of input parameters, minimal computational requirements and the adaptability for components with different construction and design features make the TEE modelling technique an ideal tool for optimized dynamic operation [11], [21].

This paper reviews the state-of-the-art for thermoelectric modelling and dynamic rating of two major components of the OWPP export system: HV/MV cables and transformers. The potential issues and risks involved in using the prominent methods for dynamic modeling of these components in windfarm applications are also discussed. The remaining paper is organized as follows: Initially, section 2 unfolds the simplified transmission system for OWPPs and identifies the critical components that cause constrictions in the system. Later, sections 3 and 4 present state-of-the-art for dynamic thermoelectric modeling of transformers and cables respectively. The state-of-the-art includes a review of recommended loading guides by IEC, IEEE and CIGRE, along with some prominent publications discussing conventional and advanced models. 


\section{OPTIMIZATION OF OWPP EXPORT SYSTEMS}

The Offshore Wind Power Plant (OWPP) export system based on HVAC technology, as identified in Fig.1, has an offshore substation close to the wind turbines and an onshore substation on land which serves as an interface between the export system and the transmission grid. Whereas the number of reactor substations depends upon the windfarm's distance from the shore. This system consists of a number of HV components ranging from $\mathrm{HV} / \mathrm{MV}$ cables and transformers to Shunt Reactors, HV filters, Gas Insulated Switchgears (GIS) and compensators (incl. STATCOM, FACTS, SVC etc.).

The long export cables (underground and subsea) are used rather conservatively because of the associated capital investment and are known to be the primary bottlenecks in this system. On the other hand, the system bottleneck can often move to the main transformers during contingency or planned/unplanned maintenance. Moreover, both these components are often over-dimensioned and consequently underutilized [22]. Therefore, optimized utilization of these 2 components using dynamic rating beyond their design limits for certain periods becomes crucial for optimization of OWPP export system. Publications discussing the utilization of unused potential of components including reactors, $\mathrm{HV}$ filters and GIS are rare, primarily because this is seldom a problem in today's system. Based on this analysis, this paper focuses only on thermal estimation of transformers and cables for offshore windfarm transmission systems.

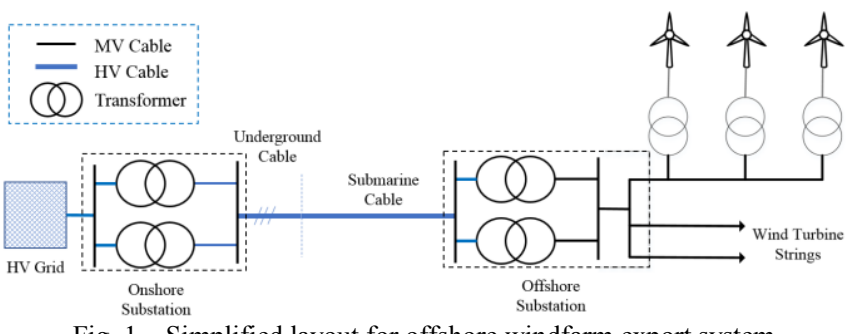

Fig. 1. Simplified layout for offshore windfarm export system

\section{THERMOELECTRIC MODELLING OF TRANSFORMERS}

The loading capability of a transformer is directly dependent on its Hot Spot (HST) and Top Oil (TOT) temperatures [14], [23]-[24]. In order to optimize the electrical export systems of offshore windfarms with transformers as one of the bottlenecks, real-time estimation of HST and TOT to calculate their dynamic loadability is a cost-effective solution. However, the estimation of these temperatures in oilfilled transformers is difficult as compared to cables because of the complicated heat transfer phenomenon [25].

The Thermoelectric Equivalent (TEE) methodology uses the analogy between principles of thermodynamics and charge/discharge mechanism of the RC-circuit, which makes it easier to grasp for electrical engineers [26]. The structures of almost all the differential equations-based TEE models discussed in this paper are directly or indirectly inspired by the circuit of Fig. 2 based on (1), which was originally coined in [27], [28] for temperature development in electrical machines and is also known as the Exponential Law.

$$
q=C_{t h} \frac{d \theta^{\prime}}{d t}+\frac{\theta^{\prime}-\theta}{R_{t h}}
$$

Here $q$ represents the heat generated by losses (analogous to current), $\theta^{\prime}-\theta$ is the temperature difference (analogous to voltage), while $C_{t h}$ and $R_{t h}$ are the thermal capacitance and thermal resistance (analogous to electrical capacitance and resistance) and $t$ represents the time. The TEE circuit of Fig. 2 can be used to estimate both the TOT and HST for transformers by substituting the relevant variables with the parameters of Table I, as originally suggested by Swift in [26]. Where $q_{f e}$ and $q_{w d g}$ represent iron and winding copper losses; $\vartheta_{\text {tot }}, \vartheta_{\text {hst }}$ and $\vartheta_{\text {amb }}$ are the top-oil, hot-spot and ambient temperatures respectively; $R_{\text {th oil-air }}$ and $R_{\text {th }}$ wdg-oil are non-linear oil-to-air and winding-to-oil thermal resistances; $C_{\text {th oil }}$ and $C_{t h}$ $w d g$ represent the thermal capacitance for oil and winding.

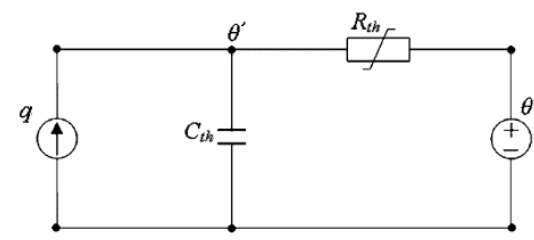

Fig. 2. Generic thermoelectric equivalence circuit for transformer temperature estimation (Hot-Spot and Top-Oil) [26]

TABLE I. PARAMETERS FOR TOT AND HST ESTIMATION (FIG. 2)

\begin{tabular}{|c|c|c|}
\hline Variable & TOT & HST \\
\hline $\boldsymbol{q}$ & $q_{\text {fe }}+q_{\text {wdg }}$ & $q_{\text {wdg }}$ \\
\hline $\boldsymbol{\theta}^{\prime}$ & $\vartheta_{\text {tot }}$ & $\vartheta_{\text {hst }}$ \\
\hline $\boldsymbol{R}_{\text {th }}$ & $R_{\text {th oil-air }}$ & $R_{\text {th } w d g-o i l}$ \\
\hline $\boldsymbol{C}_{\boldsymbol{t h}}$ & $C_{\text {th oil }}$ & $C_{\text {th } w d g}$ \\
\hline $\boldsymbol{\theta}$ & $\vartheta_{\text {amb }}$ & $\vartheta_{\text {tot }}$ \\
\hline
\end{tabular}

\section{A. Historical Development of Transformer TEE Models}

The TEE models presented in renowned loading guides by IEC and IEEE have certain limitations. Therefore, over the years numerous publications can be found offering simplifications, clarifications and recommendations for improvement of these guides. Some of the prominent ones along with the international loading guides are mentioned.

1) IEEE C57.91 Loading Guide [14], [29]-[31]:

The industry-wide accepted loading guides of IEEE [14], [29]-[31] have evolved significantly over the last 3 decades. These guides utilize the exponential law of (1) or its approximation to calculate the final TOT and HST rise. The ultimate temperature rise is estimated using the principle that the generated heat $q$ is dissipated through conduction, convection and radiation. Whereas, the Poisseulle's law of flow is applicable with the assumption that there is minimal turbulence in the oil ducts, as suggested by Montsinger in [32]. Consequently, the impact of transformer cooling modes is considered. A number of publications prove that these models perform inadequately for low $\vartheta_{a m b}$, and the calculated temperature rise is vulnerable to transients and load changes, which is extremely important for windfarm applications because of wind energy's intermittent nature [33]-[35].

\section{2) IEC Loading Guides [15], [20], [23]:}

The former IEC loading guide 60354 [15] and its improvements 60076 [23]-[24] propose 2 different methods: differential and exponential. The former is the same as IEEE C57.91; while the latter, exponential-based, is only suitable for step-load change and is dependent on arbitrarily obtained parameters. This uncertainty is resolved by a number of publications discussing extension, parameter estimation and experimental elaboration for the exponential model of IEC 60076-7 [36]-[38]. However, the dependence of this model on transformer construction-specific parameters obtainable 
only through prolonged heat-run tests makes it impractical for widescale OWPP optimization.

3) Swift et al. [26], [39] (2001):

The simplified description of the thermal-electrical analogy based on the convective heat transfer and its application to determine a transformer's HST and TOT are discussed in this model. Like the differential models of loading guides, it is essentially based on Fig. 2, i.e. it assumes the conditions for lumped capacitance, but it distinctively introduces two different circuits for heat transfer: winding-tooil and oil-to-air. The impact of cooling mode is also addressed differently. The reasons for its limited accuracy are addressed in [40] and [41].

\section{4) Susa et al. [33]-[34], [42]-[43] (2013)}

The time delay between TOT and HST rise, as measured and quantified in [25], results in HST which is higher than the one calculated by IEC loading guides. The model in [33] builds upon the discussion of Swift's model and incorporates the impact of temperature change on the thermal characteristics of transformer oil in TOT and HST calculations, thereby increasing the accuracy of calculations during transient states. The model focuses on the nonlinearity of the thermal resistance and primarily includes oil viscosity changes and loss variations with temperature, and it is further improved in [34] and [42].

\section{5) Djamali [17], [18] (2017)}

The model calculates the TOT for indoor distribution transformers and extends the findings of Swift and Susa by further addressing the heat transfer due to conduction, radiation and ventilation in the transformer room. Therefore, the transformer's loadability can be estimated using the room's ventilation temperature. Transformers in offshore platforms can be placed indoors with controlled temperature, therefore the analysis seems practically viable.

\section{6) Josue [44] (2012)}

Like Susa, this model modifies the IEC 60076-7 loading guides by investigating the variation of transformer oil viscosity with temperature, along with the dependence of winding losses on temperature. The oil temperature is equated to the HST to determine the change in its viscosity and simulate the extreme condition.

\section{7) Miscellaneous Models}

Besides the models mentioned above, there are many models that suggest improvements to the loading guides. For example, [45] investigates the influence of weather conditions (including wind speed and solar radiation) on transformer's TOT, [37] extends these models for smaller transformers, while [38] assesses a transformer's overload capability by estimating standardized error in TOT calculation but uses the design information of the transformer to estimate the heat transfer modes in it. On the other hand, [46] offers a unique perspective of identifying the sources of errors in dynamic modeling of transformers.

\section{8) Machine Learning based Models}

With the increasing computing capacity, the use of machine learning to effectively calculate the TOT and HST of transformers has also been discussed from time and again. Tang et al. in [47], [48] take the inspiration from artificial neural networks to use a genetic algorithm for identification of global solutions to estimate thermal parameters $R_{t h}$ and $C_{t h}$. The model also incorporates the impact of cooler states (on/off) prior to parameter estimation. Similarly, [49] uses the same approach for cast-resin dry-type transformers. Other methods range from neural networks [50] to neuro-fuzzy ones [51]. Moreover, the practicality of using evolving fuzzy networks is also evaluated [52]. However, the application of such models would require ample training data, which is unfortunately not readily available in today's power systems.

\section{B. Structural Evaluation of Selected Models}

The evaluation of TOT and HST estimation for 3 main differential equations-based TEE models is performed. The loading guides models, originally presented as exponential solutions in [24], [29], are converted into the respective differential equations to maintain structural homogeneity.

$$
\begin{gathered}
\text { 1) Loading Guides IEC and IEEE [24], [29] } \\
\tau_{0} \frac{d \vartheta_{t o t}}{d t}=\Delta \vartheta_{o r}\left(\frac{K(t)^{2} R+1}{R+1}\right)^{n}-\left[\vartheta_{t o t}(t)-\vartheta_{a m b}(t)\right] \\
\tau_{h} \frac{d \vartheta_{h s t}}{d t}=\Delta \vartheta_{h r} K(t)^{2 m}-\left[\vartheta_{h s t}(t)-\vartheta_{t o t}(t)\right]
\end{gathered}
$$

2) Swift et al. [26], [39]

$$
\begin{gathered}
\tau_{0} \frac{d \vartheta_{t o t}}{d t}=\Delta \vartheta_{o r} \frac{1}{n}\left(\frac{K(t)^{2} R+1}{R+1}\right)-\left[\vartheta_{t o t}(t)-\vartheta_{a m b}(t)\right]^{\frac{1}{n}} \\
\tau_{h} \frac{d \vartheta_{h s t}}{d t}=\Delta \vartheta_{h r^{\frac{1}{m}}} K(t)^{2}-\left[\vartheta_{h s t}(t)-\vartheta_{t o t}(t)\right]^{\frac{1}{m}}
\end{gathered}
$$

$$
\begin{gathered}
\text { 3) Susa et al. [33], [34] } \\
\tau_{0} \frac{d \vartheta_{t o t}}{d t}=\Delta \vartheta_{o r}\left(\frac{K(t)^{2} R+1}{R+1}\right)-\left(\frac{\vartheta_{t o t}(t)-\vartheta_{a m b}(t)}{\left[\mu_{p u}(t) \Delta \vartheta_{h r}\right]^{1-n^{\prime}}}\right)^{1 / n^{\prime}} \\
\tau_{h} \frac{d \vartheta_{h s t}}{d t}=\Delta \vartheta_{h r} K(t)^{2} P_{p u}\left(\vartheta_{h s t}\right)-\left(\frac{\vartheta_{h s t}(t)-\vartheta_{t o t}(t)}{\left[\mu_{p u}(t) \Delta \vartheta_{h r}\right]^{1-m^{\prime}}}\right)^{1 / m \prime}
\end{gathered}
$$

Where $\vartheta_{a m b}$ is the ambient temperature $\left({ }^{\circ} \mathrm{C}\right) ; K$ is the transformer load current in p.u. with rated load current as base; $\vartheta_{\text {tot }}$ and $\vartheta_{\text {hst }}$ are the calculated Top Oil and Hot Spot Temperatures respectively, expressed in ${ }^{\circ} \mathrm{C} ; \mathrm{R}$ is the ratio of load losses to no-load losses at rated load; $\Delta \vartheta_{\text {or }}$ is the TOT rise over ambient temperature $\vartheta_{a m b}$ at rated load $\left({ }^{\circ} \mathrm{C}\right)$, while $\Delta \vartheta_{h r}$ is the rated HST rise over TOT for rated load of $1 \mathrm{pu}$. The estimation of $\mu_{p u}$ (temperature dependent oil viscosity in pu) and $P_{p u}\left(\vartheta_{h s t}\right)$ (variation of load losses with HST in pu) can be performed using [33], [34]. The empirically derived exponents $n, m, n$ ' and $m$ ' have been extensively researched for almost a century and the values vary with the transformer cooling mode (i.e. ONAN, ONAF etc.), the mass distribution of transformer components [30] and oil flow type (i.e. the presence or absence of turbulence in oil flow) [25], the values for which are provided in Table II [24], [34].

The thermal time constants for oil $\tau_{0}$ and winding $\tau_{h}$ are usually obtained using the heat run test, but $\tau_{0}$ can also be estimated using slightly differing methods. The IEEE guides [29], [30] use manufacturer-defined rated losses and $\Delta \vartheta_{\text {or }}$ for ODAF cooling $(n, m=1)$ but require additional manipulation for $(n<1)$. Similarly, IEC 60076-2 [20] uses real-time loaddependent temperature rise, while IEC 60076-7 [24] recommends using the average oil temperature rise instead. It 
must also be mentioned that IEC 60076-7 recommends the use of a correction factor $(<1)$ for oil time constants to compensate for the mismatch between the time constants for top oil and average oil in ONAN and ONAF transformers, as scrutinized by Nordman et al. in [25]. All of these techniques require detail information regarding the mass and material of different transformer components (winding, oil, core etc.).

Referring to (2) - (7), it can be concluded that the basic structure of the 3 selected models is similar. The first-order non-linear differential equations have 3 basic terms: Rate of temperature change on the left-hand side, Heating-term which is dependent on load losses and Cooling-term which is dependent on relevant temperature difference. The inclusion of oil viscosity in Susa (6)-(7) is accurately reflected in the cooling-term. The major difference in the 3 models is the location of empirical constants. The models from loading guides (2)-(3) and Swift (4)-(5) distinctively place these constants on the heat-in term, while the Susa model does otherwise, which appears to be thermodynamically accurate.

TABLE II. EMPIRICAL CONSTANTS FOR IEEE [29], SWIFT [26] AND SUSA [34] MODELS

\begin{tabular}{|c|c|c|c|c|}
\hline \multirow{2}{*}{ Transformer Cooling Mode } & \multicolumn{2}{|c|}{ IEEE C57.91 } & \multicolumn{2}{|c|}{ Susa et al. $^{\text {a }}$} \\
\cline { 2 - 5 } & $\boldsymbol{n}$ & $\boldsymbol{m}$ & $\boldsymbol{n}^{\prime}$ & $\boldsymbol{m}^{\boldsymbol{\prime}^{\prime}}$ \\
\hline Oil Natural Air Natural (ONAN) & 0.8 & 0.8 & 0.8 & 0.67 \\
\hline Oil Natural Air Forced (ONAF) & 0.9 & 0.8 & 0.83 & 0.67 \\
\hline Oil Forced Air Forced (OFAF) & 0.9 & 0.8 & 0.83 & 0.67 \\
\hline Oil Directed Air Forced (ODAF) & 1.0 & 1.0 & 0.83 & 0.67 \\
\hline
\end{tabular}

\section{Discussion regarding DTR of Transformers in OWPP}

The models presented earlier have some inherent limitations for OWPP application. IEEE and IEC loading guides have accuracy limitations, Swift models perform inadequately when forced convection is used for cooling, whereas the complexity of the other methods make them less suitable for real-time dynamic rating applications.

The various sources for harmonics amplification in OWPPs including long HVAC cables, power electronic converters etc. [53] can increase the lifetime reduction phenomena in transformers for rated load. Therefore because of increased losses, load reduction becomes necessary [29], [54]. Hence, the incorporation of these losses in transformer DTR modelling is compulsory for accurate HST and TOT determination. Similarly, the transformer oil viscosity can vary significantly with temperature and this variation depends on the type of oil used and the variation is maximum for low ambient temperatures, which is common in OWPP applications [55]. The development of TOT and HST is therefore influenced by the type of transformer oil because viscosity affects the flow patterns and convective cooling.

\section{CABles LoAdability \& Thermoelectric Modelling}

As already discussed, cables used to transmit energy from offshore substations to the onshore ones are known to be the primary bottlenecks in OWPP export systems. This is true primarily because the associated capital costs restrict the potential provision of multiple subsea cables. Therefore, optimized loadability of cables is extremely important for a good business case. Only HVAC cables are discussed here.

\section{A. Determination of $H V / M V$ Cables Loadability for OWPP}

Like the remaining $\mathrm{HV}$ electrical components, the temperature of the insulating material defines the loadability of power cables [11]. Several cable manufactures propose 90 ${ }^{\circ} \mathrm{C}$ to be the upper limit for the conductor temperature for Cross-Linked Poly-Ethylene (XLPE) insulated cables for cyclic load, in order to prevent the dielectric and mechanical strength of the cables from deterioration and to preserve cables' life [12]. The dependence of XLPE cables' properties on temperature and the impacts of thermal ageing have been critically investigated since the introduction of these cables more than 4 decades ago. These properties include thermal resistivity, specific heat, electrical breakdown strength under $\mathrm{AC}$ and impulse voltages, tensile strength, electrical resistivity, permittivity (dielectric strength) and loss factor (tan delta) [56]-[58]. The investigation results are documented in some prominent publications [59-63].

The loadability of cables can either be defined for a permanent period (until end of life) called steady load (IEC 60287) or for shorter duration called dynamic load. In both cases, the physical limitations of the cables are never violated. Dynamic loading (IEC 60853) ensures optimal utilization of cables and can usually be of two types: cyclic (daily load cycles) or emergency (short durations) [12], [63]-[64]. Even though, these loading limits are extremely useful in OWPP applications owing to wind energy's intermittent nature, these are not readily used because of reasons already discussed.

\section{B. Dynamic Thermoelectric Modelling of HV/MV Cables}

As mentioned earlier, determination of OWPP cable HST for real-time DTR application is practically feasible only if appropriate thermoelectric models capable of performing online calculations of cable core or insulation temperature are used [65], which is not possible using IEC 60287 and 60853. An extensive literature review reveals that the major thermal models can be divided into three categories: FEM-based, Laplace transformation-based and Differential equation-based models, out of which only the last 2 models qualify as thermoelectric ones. It must also be mentioned that the exact implications of these methods are not documented well enough, essentially because different manufacturers and consultants employ these models in commercially available software such as [66]-[70]. Keeping the discussion aligned with Section 3, this section focuses particularly on Laplace and differential-based models.

\section{1) Laplace-based Models}

Laplace transformation-based methods (IEC 60853) utilize the exponential integrals to determine conductor temperature development during load change [58], [63]. The models proposed in [57], [71] use exponential integrals to evaluate the dynamic thermal response and take into account all external parameters (known and unknown) to accurately determine the cable's loadability.

\section{2) Differential Equation based Models}

The models are also based on Fig. 2 [27] and follow the same principle as TEE modeling of transformers discussed in previous section. These models are established by dividing the subcomponents of cables (conductors, insulator, screens etc.) into thermal zones with respective thermal capacitance and resistance, which is essential when analysis is not based on exponential integrals and attainment factors [72]. Moreover, the ambient conditions and variation of thermal parameters of soil (or other medium) with temperature are also considered.

The steady-state thermoelectric model of Fig. 3 for subsea cables, extracted from [11], [71] takes into account armor losses, which are crucial for subsea cables, but it is based on 
some simplified assumptions. The heat losses are represented by $W(\mathrm{~W} / \mathrm{m})$, each node represents a temperature $\theta$, while $T$ and $C$ are the thermal resistances and capacitances respectively. The subscripts definitions are critical: $c, d, s$ and $a$ represent the conductor, dielectric (insulation), screen and armor respectively. While 1, 2 and 3 are used to define the thermal parameters of dielectric, armor and surroundings respectively. The conductor temperature $\left(\theta_{C}\right)$ calculated using this model is given by (8). The sheath losses $W_{s}$ and armor losses $W_{a}$ can be calculated using the conductor losses $W_{c}$ as $\lambda_{1} W_{c}$ and $\lambda_{2} W_{c}$ respectively. Where, sheath and armor loss factors $\lambda_{1}$ and $\lambda_{2}$ can either be obtained according to IEC 60287 [11] or as per improvements in [71].

$$
\frac{d \theta_{C}}{d t}=\frac{1}{C_{1}}\left(W_{C}+\frac{1}{2} W_{d}-\frac{\Delta \theta_{C}-\Delta \theta_{S}}{T_{1}}\right)
$$

Equivalent to transformer TEE models, $\Delta \theta_{S}$ in (8) is found using a similar equation. Some publications [73]-[74] claim improved performance and accuracy by combining the differential models for a cable's internal parameterization and Fourier models for external. According to [75], machine learning and genetic algorithms are also suitable for the differential approach. Moreover, the cable surroundings are divided into multiple loops for increased accuracy, but this approach can be computationally expensive.

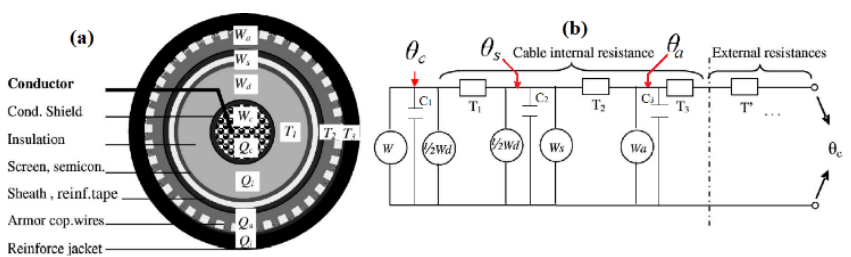

Fig. 3. Single Core Cable Layout. (a) Cross-section. (b) Thermal network for dynamic rating operation [52]

\section{Discussion regarding DTR of Cables in OWPP}

The information of ambient conditions including temperature, thermal properties etc. of the cable's surrounding material (soil, water etc.) is used as inherent input to almost all the models discussed earlier, which makes it extremely critical [57], [71]. This information is either estimated, measured or both. Temperature measurements along cables are performed using PT100 sensors, thermocouples or opticalfibres. But the length of offshore cables for OWPPs result in precision issues which may consequently miss the possible hotspot development [74]. Moreover, there can be inherent hot-spots in OWPP cable installations (E.g. J-tubes and landfills), which cause major bottlenecks. Also, the cable length creates significant complications (including harmonics) which must be accounted for in the thermoelectric models [75]. A number of advanced measurement and monitoring methods can be used to improve these models. These methods include Time-Domain Reflectometers, Distributed Temperature Sensing (DTS), Line Resonance Analysis (LIRA) and Distributed Acoustic Sensing (DAS).

\section{CONCLUSION}

A comprehensive study has been conducted on transmission system optimization for offshore windfarms. Transformers and cables are identified as the potential bottlenecks in the windfarm export system. The relevant thermoelectric modeling techniques proposed over the last few decades, which can be used to overcome the congestion challenges in the network based on dynamic thermal estimation have been mentioned. Some of these techniques are primarily based on industry-wide accepted IEEE and IEC loading guides. But the limitations of these models have been extensively worked out in several recent publications suggesting model improvements. All these techniques have been thoroughly reviewed in this paper and the potential risks for offshore windfarm applications have also been identified.

\section{ACKNOWLEDGMENT}

Authors would like to thank Innovation Fund Denmark and Ørsted Offshore A/S for supporting the work. The OPTIMUM framework project collaboration between DTU, Energinet.dk and Ørsted oversees this work.

\section{REFERENCES}

[1] Environmental Report 2017 - 'Environmental report for Danish electricity and CHP for 2016 status year,' Energinet.dk

[2] 'Denmark's Energy and Climate Outlook 2017' Danish Energy Agency, March 2017

[3] 'Energy Agreement: Danish Climate Policy Plan Towards a Low Carbon Society', Danish Government, 2018,

[4] S. Abbott, S. Abdelkader 'Experimental Validation \& Comparison of IEEE, CIGRE Dynamic Line Models', IEEE - Universities Power Engineering Conference, 2010 45th International, Wales, Dec 2010

[5] W. Winter, K. Elkington 'Pushing the Limits: Europe's New Grid: Innovative Tools to Combat Transmission Bottlenecks \& Reduced Inertia', IEEE Power Energy Magazine, Vol 13, Dec 2014, pp 60-74

[6] N. Alguacil, M. H. Banakar and F. D. Galiana, "Electrotherma coordination part II: case studies," IEEE Transactions on Power Systems, vol. 20, no. 4, pp. 1738-1745, Nov. 2005

[7] CIGRE WG B2.43, "Guide for thermal rating calculations of overhead lines", Technical Brochure 601, Paris, France 2014

[8] IEEE Standard 738, "IEEE Standard for calculating the currenttemperature relationship of bare overhead conductors", IEEE Standard Association, Washington, U.S.A 2014

[9] S. M. Mahajan, U. M. Singareddy, 'A Real-Time Conductor Sag Measurement System Using a Differential GPS', IEEE Transactions on Power Delivery, Vol. 27 Issue: 2, Apr 2012, pp 475 - 480

[10] CIGRE WG B1.45, 'Thermal Monitoring of Cable Circuits and Grid Operators' Use of Dynamic Rating Systems', CIGRE 2016

[11] IEC, 60287-1-1. electric cables - calculation of the current rating (100 \% load factor) and losses - general," IEC, Tech. Rep., 2006

[12] IEC 60853-1. calculation of cyclic, emergency current rating of cables up to and including 18/30 (36) kv,' IEC, Tech. Rep., 1985.

[13] CIGRE WG B1.02, 'Optimization of Power Transmission Capability of Underground Cable Systems Using Thermal Monitoring' Technical brochure 247, Paris, France, Apr 2004

[14] 'IEEE C57.91: IEEE Guide for Oil-Immersed Transformers', 2004

[15] 'IEC 60354- Loading Guide for Oil-Immersed Transformers', 1991

[16] Lapworth, J., Picher, P., Channet, J., et al.: 'Transformer thermal modelling'. Technical report, Cigre Working Group A2.38, 2016

[17] M. Djamali, S. Tenbohlen, 'Real-Time Evaluation of the Dynamic Loading Capability of Indoor Distribution Transformers,' IEEE Transactions on Power Delivery Vol. 33, Jun 2018, pp 1134 - 1142

[18] M. Djamali and S. Tenbohlen, "Assessment of the dynamic overload capability of distribution transformers," in the 19th International Symposium on High Voltage Engineering (ISH), 2015.

[19] H. Li, 'Assessment of underground cable ratings based on distributed temperature sensing,' IEEE Transactions on Power Delivery, vol. 21 , no. 4, pp. 1763-1769, 2006

[20] IEC 60076-2: Power Transformers-Temperature rise', April 1993

[21] M. Djamali, S. Tenbohlen, 'Hundred years of experience in the dynamic thermal modelling of power transformers,' IET Gener. Transm. Distrib., 2017, Vol. 11 Iss. 11, pp. 2731-2739

[22] M. H. Banakar, N. Alguacil and F. D. Galiana, 'Electrothermal coordination I: theory and implementation schemes,' IEEE Transactions on Power Systems, vol. 20 pp. 798-805, May 2005. 
[23] IEC, 'IEC 60076-7:2018 power transformers - part 7: Loading guide for oil-immersed power transformers', vol. 60076, no. 7, 2018.

[24] IEC, "IEC 60076-7:2005 power transformers - part 7: Loading guide for oil-immersed power transformers," vol. 60076, no. 7, 2005.

[25] Nordman, H., Rafsback, N., Susa, D.: 'Temperature responses to step changes in the load current of power transformers', IEEE Trans. Power Deliv., 2003, 18, (1), pp. 107-112

[26] G. Swift, T. S. Molinski, 'A fundamental approach to transformer thermal modeling. Part I: Theory and equivalent circuit', IEEE Trans. Power Del., vol. 16, no. 2, pp. 171-175, Apr.2001.

[27] Goldschmidt, R.: 'Temperature curves and the rating of electrical machinery', J. Inst. Electr. Eng., 1905, 34, (172), pp. 660-691

[28] Montsinger, V.M.: 'Effect of load factor on operation of power transformers', Trans. Electr. Eng., 1940, 59, (11), pp. 632-636

[29] IEEE Std C57.91-2011: IEEE Guide for Loading Mineral-OilImmersed Transformers and Step-Voltage Regulators', Dec 2011

[30] 'IEEE guide for loading mineral oil immersed overhead and padmounted distribution transformers rated $500 \mathrm{kVA}$ and less with 65 C or 55 C average winding rise', 1981

[31] IEEE Std C57.91-1995: IEEE Guide for Loading Mineral-OilImmersed Transformers and Step-Voltage Regulators', Dec 1995

[32] Montsinger, V.M., Cooney, W.H.: 'Temperature rise of stationary electrical apparatus as influenced by radiation, convection and altitude', Am. Inst. Electr. Eng., 1924, 43, (9), pp. 803-812

[33] D. Susa, M. Lehtonen, and H. Nordman, 'Dynamic thermal modeling of power transformers', IEEE Trans. Power Del., vol. 20, no. 1, pp.197-204, Jan. 2005.

[34] D.Susa, M. Lehtonen 'Dynamic Thermal Modeling of Power Transformers: Further Development-Part I' IEEE transactions on power delivery, vol. 21, no. 4, October 2006, pp 1961 - 1970

[35] S. H. H. Kazmi, J. Holbøll, T. H.Olesen, T. S. Sørensen, 'Dynamic Thermoelectric Modelling of Oil-filled Power Transformers for Optimization of Offshore Windfarm Export Systems,' CIGRE Symposium Aalborg, 2019, in press

[36] D. Susa, H. Nordman, 'IEC 60076-7 loading guide thermal model constants estimation' Int. Trans. Electr. Energ. Syst. 2013; 946-960

[37] B. Das, T. Jalal 'Comparison \& Extension of IEC Thermal Models for Dynamic Rating of Distribution Transformers' POWERCON IEEE International Conference Power System Tech, 2016

[38] M. Djamali, S. Tenbohlen, 'Malfunction Detection of the Cooling System in Air-Forced Power Transformers Using Online Thermal Monitoring' IEEE transactions on power delivery, v. 32, no. 2, 2017

[39] G. Swift, T. Molinski, R. Bray, 'A fundamental approach to transformer thermal modeling. Part II: Field verification', IEEE Trans. Power Del., vol. 16, no. 2, pp. 176-180, Apr. 2001.

[40] O. Amoda, D. J. Tylavsky, G. A. McCUlla, 'Acceptability of Three Transformer Hottest-Spot Temperature Models', IEEE Transactions on Power Delivery, vol. 27, pp. 013-022, Jan 2012

[41] Jauregui-Rivera, L., Tylavsky, D.: 'Acceptability of four transformer top-oil thermal models. Part i: Defining metrics', IEEE Trans. Power Deliv., 2008,23, (2), pp. 860-865

[42] D.Susa, M. Lehtonen 'Dynamic Thermal Modeling of Power Transformers: Further Development-Part II' IEEE transactions on power delivery, vol. 21, no. 4, October 2006, pp 1971 - 1980

[43] D. Susa, M. Lehtonen, and H. Nordman, 'Dynamic thermal modeling of distribution transformers', IEEE Trans. Power Del., vol. 20, no. 3 , pp. 1919-1929, Jul. 2005.

[44] F. Josue, R. Saers, 'Transformer Hot-Spot Temperature Estimation for short-time dynamic loading' IEEE International Conference on Condition Monitoring and Diagnosis, 23-27 Sept. 2012

[45] I. Arifianto, R. Saers, 'Investigation of transformer top-oil temperature considering external factors,' IEEE International Conf. on Condition Monitoring and Diagnosis, Sept 2012, pp 198 - 201

[46] D. J. Tylavsky, Q. He, 'Sources of Error in Substation Distribution Transformer Dynamic Thermal Modeling' IEEE transactions on power delivery, vol. 15, no. 1, Jan 2000, pp. 178 - 185

[47] W.H. Tang, Q.H. Wu, 'Equivalent heat circuit-based power transformer thermal model' IEE Proc-Electr. Powr Appl., Vol. 149, March 2002, pp 87 - 92

[48] W.H. Tang, Q.H. Wu, 'A Simplified Transformer Thermal Model Based on Thermal-Electric Analogy,' IEEE transactions on power delivery, vol. 19, July 2004, pp 1112 - 1119
[49] D. Azizian, M. Bigdeli, 'A Dynamic Thermal Based Reliability Model of Cast-Resin Dry-Type Transformers' International Conference on Power System Technology, 2010

[50] He, Q., Si, J., Tylavsky, D.: 'Prediction of TOT for transformers using ANN', IEEE Trans. Power Deliv., 2000, pp. 1205-1511

[51] Hell, M., Costa, P.J., 'Participatory learning in powertransformers thermal modeling', IEEE Trans. Power Deliv., 2008, pp.2058-2067

52] Souza, L.M., Lemos, A.P., Caminhas, W.M., et al.: 'Thermal modeling of power transformers using evolving fuzzy systems', Eng. Appl. Artif. Intell., 2012, 25, (5), pp. 980-988

[53] L. H. Kocewiak, S. K. Chaudhary, Bo Hesselbæk, "Harmonic Mitigation methods in Large Offshore WPPs," 12th Wind Integration Workshop, 2013, pp 443-448

[54] 'IEEE std C57.110 Recommended Practice for Establishing LiquidFilled and Dry-Type Power and Distribution Transformer Capability When Supplying Nonsinusoidal Load Currents', Mar 2008

[55] Al-Amin H., O'Brien J., Lashbrook M.: 'Synthetic ester transforme fluid: a total solution to windpark transformer technology', Renew. Energy, 2013, 49, pp. 33-38

[56] Olsen, R. S., Holbøll, J., \& Guðmundsdottir, U. S. (2013). 'Dynamic Loadability of Cable Based Transmission Grids. Technical University of Denmark, Department of Electrical Engineering'

[57] G. Anders, A. Napieralski, 'Advanced modeling techniques for dynamic feeder rating systems," IEEE Transactions on Industry Applicaitons, vol. 39, no. 3, pp. 619-626, 2003.

[58] R. J. Millar, 'A comprehensive approach to real time power cable temperature prediction and rating in thermally unstable environments' PhD Dissertation, Helsinki University of Technology, Finland, 2006

[59] X. Qi and S. Boggs, 'Thermal and mechanical properties of epr and xlpe cable compounds,' IEEE Electrical Insulation Magazine, vol. 22, no. 3, pp. 24, May/June 2006.

[60] R. Eichhorn, 'A critical comparison of xlpe epr for use as electrical insulation on underground power cables,' IEEE Transactions on Electrical Insulation, vol. EI-16, no. 6, pp. 469-482, Dec 1981.

[61] C. Green, A. Vaughan, G. Stevens, 'On the temperature dependence of electrical and mechanical properties of recyclable cable insulation materials based upon polyethylene blends,' Conference on Electrical Insulation and Dielectric Phenomena, 2011, pp. 36-39

[62] M. Nedjar, 'Thermal aging on the electrical properties of crosslinked polyethylene," Journal of Applied Polymer Science, vol.111, pp. 1985-1990, Oct 2009

[63] IEC 60853-2. calculation of the cyclic and emergency current rating of cables - greater than 18/30 (36) kv' - IEC, Tech. Rep., 1989.

[64] IEC 60853-2:2017 - Calculation of the cyclic and emergency current rating of cables. Part 2: greater than $18 / 30(36) \mathrm{kV}$

[65] B.J. Grotenhuis, J.E. Jaspers, 'Increasing the capacity of cable systems using cable asset management based on thermal and mechanical properties' 16th International Conference and Exhibition on Electricity Distribution, 2001

[66] ABB,Network manager scada dms,ABB, Sweden,Tech. Rep., 0215,

[67] Cymcap, December 2017.

[68] Siemens Energy, November 2018

[69] Areva T\&D, 'e-terraplatform - the power to adapt!' 2005.

[70] De Wild, F. Meijer, and E. Geerts, 'Extracting more value from intelligent cable systems', August 2004, Transmission and Distribution World, pp. 22-27

[71] G. J. Anders, H. Brakelmann, 'Improvement in cable rating calculations by consideration of dependence of losses on temp," IEEE Transactions on Power Delivery, vol. 19, pp. 919-925, 2004.

[72] R. Olsen, J. Holboll, and U. Gudmundsdottir, 'Dynamic temperature estimation and real-time emergency rating of transmission cables,' in IEEE Power \& Energy Society General Meeting. IEEE, July 2012.

[73] S.-H. Huang, W.-J. Lee, and M.-T. Kuo, 'An online dynamic cable rating system for an industrial power plant in the restructured electric market,' IEEE Transactions in Industry Applications, vol. 43, no. 6 , pp. 1449-1458, 2007

[74] T. Igi, H. Komeda, and S. Mashio, 'Study of the dynamic rating of a $138 \mathrm{kv}$ xlpe cable system by optical fiber monitoring," in 8 th International Conference on Insulated Power Cables, 2011

[75] M. Sakata and S. Iwamoto, 'Genetic algorithm based real-time rating for short-time thermal capacity of duct installed power cables,' International Conference on Intelligent Systems Applications to Power Systems, ISAP, 1996, pp. 85-90. 